\title{
A GESTÃO DO CONHECIMENTO NAS ORGANIZAÇÕES
}

\section{ARTIGO ORIGINAL}

MURIRIUA, Eduardo dos Santos Arlindo ${ }^{1}$

MURIRIUA, Eduardo dos Santos Arlindo. A gestão do conhecimento nas organizações. Revista Científica Multidisciplinar Núcleo do Conhecimento. Ano. 06, Ed. 12, Vol. 09, pp. 05-17. Dezembro de 2021. ISSN: 2448-0959, Link de acesso: https://www.nucleodoconhecimento.com.br/comunicacao/conhecimento-nasorganizacoes, DOI:

10.32749/nucleodoconhecimento.com.br/comunicacao/conhecimento-nasorganizacoes

\section{RESUMO}

A Gestão do Conhecimento permite o registro de todo o conhecimento gerado em uma organização. O objetivo desse armazenamento de dados e informações é o seu uso no futuro, seja ele distante ou próximo. Portanto, a Gestão do Conhecimento é uma forma de valorizar e enriquecer a qualidade dos dados, que são elementos tangíveis e, no geral, abundantes dentro das organizações. Diante desse contexto, este artigo tem como questão-norteadora: Qual a importância da gestão do conhecimento nas organizações? Portanto, o trabalho tem por objetivo demonstrar a importância da gestão do conhecimento nas organizações. Quanto à metodologia, optou-se por uma abordagem exploratória e, para a coleta de dados, foi realizada uma pesquisa bibliográfica. A partir dela, propõe-se uma revisão de literatura. Com base na pesquisa, chegou-se ao seguinte resultado: 0 gerenciamento do conhecimento organizacional é um elemento importante nas organizações pois a

\footnotetext{
${ }^{1}$ Mestrando em Administração e Regulação de Educação pela Academia Militar Marechal Samora Machel de Nampula e Licenciado, Curso de Relações Publicas e Comunicação Estratégica pela Universidade Católica de Moçambique- Faculdade de Ciências de Educação e Comunicação de Nampula. ORCID: http:/Orcid.Org/ 00000002-8063-9095.

RC: 103793

Disponível em:

https://www.nucleodoconhecimento.com.br/comunicacao/conhecimento-nasorganizacoes
} 
aprender, a criar e a converter esse conhecimento em ações práticas e eficientes, o que implica preparar o ambiente organizacional como um todo para que isto seja viável.

Palavras-chave: Estratégia, Comunicação e sucesso empresarial.

\section{INTRODUÇÃO}

As organizações na sociedade contemporânea têm se deparado com um desafio global e diário: a necessidade de se reinventar e inovar ao fazer uso do conhecimento (ALFENAS et al., 2021). A sobrevivência em um mercado altamente competitivo também é um desses desafios. A fim de que tais empresas consigam manter a sua vantagem competitiva, precisam aprender a gerir informações com as quais têm contato a partir dos seus gestores e colaboradores (MENEZES et al., 2017). Aprender a planejar e tomar decisões de forma rápida e precisa são atividades associados ao campo da gestão do conhecimento. Nesse sentido, uma preocupação das organizações contemporâneas é a administração da gestão do conhecimento a partir de seus processos organizacionais. A informação, quando tratada e colocada em prática, gera conhecimento e, consequentemente, a organização passa a ter uma maior vantagem competitiva (MOLINA, 2010).

A gestão do conhecimento no ambiente organizacional é de suma importância, pois parte-se da hipótese de que o conhecimento compreendido pode ser utilizado como um recurso estratégico, o que fez com que ele passasse a ser considerado como um ativo intangível (SANTOS; DAMIAN; VALENTIM, 2019). Todavia, com a transformação do conhecimento em ativo intangível, a sua gestão se torna essencial, uma vez que a sua correta administração permite que o saber, técnicas, métodos e ferramentas, junto ao conhecimento, possam ser disseminados entre os colaboradores (STRAUHS, 2012). Diante desse intercâmbio, que faz com que o conhecimento circule na organização, novos saberes são gerados diariamente, porém, para que ele seja convertido em ações práticas, eficientes e coerentes

RC: 103793

Disponível em:

https://www.nucleodoconhecimento.com.br/comunicacao/conhecimento-nas-

organizacoes 
àquele contexto, é necessário que haja condições necessárias para que a organização possa criar estratégias diferenciais para adquirir uma maior vantagem competitiva e aumento no desempenho diário, individual e coletivo (ALFENAS et al., 2021).

A empresa, por sua vez, ao adquirir uma maior vantagem competitiva, consegue se transformar em uma organização amparada pelo conhecimento, o que faz com que o seu desempenho seja superior (MOLINA, 2010). Assim sendo, as organizações, na sociedade contemporânea, têm concentrado a sua atenção $e$, consequentemente, investido nas diversas ações e práticas concernentes ao campo da Gestão do Conhecimento (GC) (MATTERA, 2014). Tais ações e práticas, por sua vez, permitem a criação de mecanismos que proporcionam, aos sujeitos organizacionais, isto é, aos colaboradores, o aprendizado, a sociabilidade, bem como a disseminação de informações e conhecimentos que permitem a geração de melhorias contínuas no que toca à qualidade do trabalho, à redução de custos $\mathrm{e}$, consequentemente, ao processo de tomada de decisão (SANTOS; DAMIAN; VALENTIM, 2019). A eficiência da organização aumenta de forma significativa quando há o correto manuseio das ferramentas e técnicas do campo da Gestão do Conhecimento.

Pode-se definir a área da Gestão do Conhecimento como aquela disciplina que tem como escopo principal o estudo das estratégias, ações e práticas que podem ser executadas para o aumento da vantagem competitiva em um determinado contexto (MOLINA, 2010). A partir desse estudo, deve-se converter esse conhecimento em um projeto passível a ser implementado a partir de sistemas de gestão específicos (GUTIÉRREZ, 2008). Almeja-se, com isso, que o conhecimento tácito, explícito, individual, de ordem interna e externa, envolvido na empresa como um todo possa ser, ao mesmo tempo, transformado e convertido de forma sistemática em conhecimento organizacional e/ou corporativo (GUTIÉRREZ, 2008). Este conhecimento, por sua vez, deve se tornar acessível e deve ser passível a ser compartilhado (STRAUHS, 2012). O compartilhamento desse conhecimento gerado

RC: 103793

Disponível em:

https://www.nucleodoconhecimento.com.br/comunicacao/conhecimento-nasorganizacoes 
no interior da organização deve permitir o aumento do conhecimento individual de todos os membros que colaboram para com a entidade diariamente.

Por outro lado, além da internalização do conhecimento pelos colaboradores da entidade como um todo, a Gestão do Conhecimento deve fomentar, também, uma melhora significativa na contribuição desses sujeitos no que toca ao alcance dos objetivos pleiteados e buscados pela própria organização (MENEZES et al., 2017). Nesse sentido, é papel das organizações, ao longo de sua rotina, estimular os membros dos mais diversos setores a desenvolverem, bem como a transformarem o conhecimento gerado em valor agregado (STRAUHS, 2012). Ainda sobre o conceito de Gestão do Conhecimento, pode-se mencionar que ele, para que seja eficaz, não depende apenas do fator humano, da estrutura organizacional propriamente dita e das tecnologias da informação e comunicação que servem como base de interface para a proposição de certas estratégias (VALENTIM, 2008). Elas são relevantes, pois permitem alguns cuidados voltados ao acompanhamento e à utilização do conhecimento organizacional no processo de desenvolvimento de ações estratégicas na empresa (VALENTIM, 2008).

Além dos fatores citados, o desenvolvimento de um cultura corporativa enraizada é favorável à prática da socialização do conhecimento, porém, a fim de que seja desenvolvida, mantida e preservada, é preciso que haja um comprometimento de todos no processo como um todo (SANTOS; DAMIAN; VALENTIM, 2019). Há algumas implicações relacionadas ao uso estratégico da informação que devem ser mencionadas, sendo que elas estão interrelacionadas com a gestão do conhecimento e, desse modo, são conhecidas como as "três arenas", estando elas relacionadas com o uso da informação (CHOO, 2003). O conhecimento criado e gestado, portanto, deve criar significado para que, a partir disso, todos possam tomar decisões mais assertivas. Além disso, essas três arenas tomam forma a partir de processos que caminham de forma interligada, de modo que entende-se que essas atividades se alimentam mutuamente e promovem uma visão holística 
relacionada ao uso da informação e, consequentemente, do conhecimento $(\mathrm{CHOO}$, 2003).

Nesse sentido, é correto afirmar que a gestão do conhecimento no contexto corporativo necessita das três abordagens para que seja possível conhecer as oportunidades e as ameaças por meio do uso da informação e do conhecimento que perpassam por aquele ambiente específico e particular (MOLINA, 2010). A Gestão do Conhecimento, portanto, permite a criação de um conjunto de estratégias que coloca em prática ações voltadas à criação, aquisição, compartilhamento e utilização de ativos de conhecimento (VALENTIM, 2008). Diante desse contexto, este artigo tem como questão-norteadora: Qual a importância da gestão do conhecimento nas organizações? A fim de que a questão seja respondida, tem-se como objetivo demonstrar a importância da gestão do conhecimento nas organizações. Para tanto, apresenta-se os conceitos relacionados a ela que podem ser aplicados em uma empresa. Como objetivos específicos pretende-se abordar o processo de gestão do conhecimento, a abordagem sociológica, comportamental, econômica e tecnológica relacionadas a ela e explicitar sua contribuição para a eficiência organizacional.

Trata-se de uma pesquisa de natureza exploratória (LAKATO; ANDRADE, 2003) e, para a coleta de dados, partiu-se de uma pesquisa bibliográfica, tendo, como resultado, uma revisão da literatura.

\section{O PROCESSO DE GESTÃO DE CONHECIMENTO}

De acordo com Turban e Aronson (2001), pode-se perceber que o processo de gestão de conhecimento é composto por cinco atividades fundamentais:

- Aquisição de conhecimento - é uma atividade que envolve especialistas, livros e, como não poderia deixar de ser, sistemas informáticos (SAD). Pode ser relativo a um problema específico ou abordagem relativa ao processo de resoluções de problemas em geral.

RC: 103793

Disponível em:

https://www.nucleodoconhecimento.com.br/comunicacao/conhecimento-nas- 
- Validação do conhecimento - por meio da aplicação, verifica-se e valida-se o conhecimento até que a sua qualidade satisfaça os padrões da organização.

- Representação do conhecimento - esta atividade faz a organização do conhecimento e, depois, disponibiliza-o a partir de mapas de conhecimento.

- Inferências - engloba o desenvolvimento ou a aquisição de aplicações que deem as TIC a capacidade de inferir sobre os problemas, baseando-se no conhecimento e especificações destes.

- Explanação e justificações - cabe a esta atividade desenhar e programar capacidades de explanação, por exemplo, acerca da resolução de um problema, nomeadamente questões como «porque» ou «como».

A partir de uma abordagem mais empresarial, Santos e Ramos (2006) apresentam uma outra estrutura do processo de gestão do conhecimento, cuja ênfase é dada na partilha generalizada do conhecimento, ou seja, enquanto processo a ser levado em conta em qualquer tipo de pensamento/planeamento estratégico:

1. Criação de conhecimento - refere-se à criação de um conhecimento novo, mas não descurando a reformulação de um conhecimento já existente. Esta criação pode ser tanto a nível individual como coletivo. A nível individual, ocorre em resultado da experiência adquirida ao longo da realização das atividades ou resolução de problemas. Tem origem em processos formais de aprendizagem e da reflexão individual sobre resultados obtidos em determinada ação ou decisão.

2. Partilha e transferência de conhecimento - a utilidade desta atividade prendese à necessidade de transmitir a toda organização um conhecimento adquirido por um indivíduo ou pelo coletivo destes, com vista ao melhoramento da percepção, da decisão e comportamento da organização. Para que isso possa acontecer, a organização deve implementar processos de comunicação e fluxo de informação eficazes que permitam, inclusive, a interação à distância (exemplo, fóruns online, e-mail, aplicações especificas de gestão de conhecimento).

RC: 103793

Disponível em:

https://www.nucleodoconhecimento.com.br/comunicacao/conhecimento-nas- 
A Gestão do Conhecimento, nesse contexto, permite o estabelecimento de fluxos que garantem que a informação e o conhecimento sejam disponibilizados no tempo e no formato adequado, sendo que esses fluxos auxiliam na geração de ideias, na proposição de soluções para problemas diários diversos e na tomada de decisões como um todo (MENEZES et al., 2017). Nesse sentido, pode-se afirmar que os esforços do campo da Gestão do Conhecimento decorrem da criação de ambientes e/ou de situações que proporcionem, naquele contexto, a interação e a mobilização do saber individual para o coletivo (SANTOS; DAMIAN; VALENTIM, 2019). Essa transição se dá por meio de processos, manuais e padrões de operacionalização típicos àquele negócio, além disso, envolve-se o know-how reconhecido pelos interessados na organização como um todo (MATTERA, 2014). Entende-se que o ambiente da organização deve ser compreendido como um organismo vivo e coletivo, de modo que os ideais e as ideias permitem a criação de novos conhecimentos (NONAKA, 2008).

A fim de que o processo se dê de forma efetiva, todos ligados à organização, ou seja, que nela atuam, devem corroborar com um processo de auto renovação de ordem pessoal e organizacional (NONAKA, 2008). Diante desse cenário, concebe-se que a Gestão do Conhecimento abarca processos diversos relacionados à conversão do conhecimento tácito, compreendido como aquele internalizado e individual, para aquele explícito, isto é, construído e externalizado na coletividade organizacional (SANTOS; DAMIAN; VALENTIM, 2019). Visa-se, com isso, o autoconhecimento organizacional, que é a compreensão compartilhada dos valores, missões e objetivos defendidos pela empresa (MOLINA, 2010). É necessário saber para onde ela está indo, em que mundo deseja viver e como almeja transformar esse mundo idealizado em uma realidade por meio do conhecimento (NONAKA, 2008). Destaca-se que uma organização que cria conhecimento torna-se capaz de aumentar a sua capacidade, sobretudo quando transforma o conhecimento tácito em explícito. 
Nesse processo, o conhecimento individual deve ser convertido em conhecimento coletivo para que ações e estratégias delimitadas de forma também coletiva possam ser colocadas em prática (MATTERA, 2014). Esta ação é compreendida pelas organizações diversas como um desafio organizacional, porém, aquelas entidades que desejam se tornar criadoras de conhecimento, devem se comprometer com a implantação de práticas que devem ser coerentes com as mudanças necessárias à implantação de novas rotinas de gestão para aquele contexto (CHOO, 2003). Toda mudança demanda alguma descontinuidade nos fluxos de informação e na própria segurança adquirida ao longo do tempo, visto que são frutos de experiências e vivências oriundas daquele contexto organizacional (SANTOS; DAMIAN; VALENTIM, 2019). Assim sendo, entende-se que todo processo de mudança aponta para certas ambiguidades e, dessa forma, não encontra-se isento de resistências e de incompreensões (CHOO, 2003).

Menciona-se que, por outro lado, à partir do momento em que a organização compartilha e disponibiliza informação capaz de gerar consenso e criar espaços cognitivos e dialógicos, a conversão de informação em conhecimento se torna mais viável, fluida e efetiva (STRAUHS, 2012). Visa-se, com esse processo, a troca de experiências e vivências diversas entre os membros que colaboram com aquela organização. Como resultado desse processo, os aspectos ambíguos tendem a ser minimizados, o que pode agregar uma maior segurança aos sujeitos organizacionais (CHOO, 2003). Além disso, nessa relação, cria-se significados comuns sobre acontecimentos e situações diversas inerentes àquele contexto, conhecimento este que pode ser compartilhado, o que, consequentemente, pode desencadear ações coletivas de ordens diversas (MENEZES et al., 2017). A Gestão do Conhecimento, nesse sentido, estimula as empresas a colocarem em prática um processo sistêmico para a gestão de seus processos e atividades, apoiando-se, para isso, na transformação dos conhecimentos em ações (ALFENAS et al., 2021).

A Gestão do Conhecimento também é capaz de fazer com que aqueles processos desestruturados sejam transformados em conhecimentos organizados, sobretudo

RC: 103793

Disponível em:

https://www.nucleodoconhecimento.com.br/comunicacao/conhecimento-nasorganizacoes 
porque estimula a comunicação entre os sujeitos envolvidos de uma forma mais assertiva (SANTOS, 2014). Todavia, a fim de que essa transição seja viável àquele cotidiano, demanda-se uma mudança de postura significativa nos valores que alicerçam aquela cultura organizacional como um todo (VALENTIM, 2008). Em outras palavras, implica-se a adesão às distintas ações de cunho individual e coletivo, bem como a processos capazes de estimular a conscientização quanto às mudanças organizacionais que fomentam e impulsionam a valorização do conhecimento organizacional (NONAKA, 2008). Frisa-se que a Gestão do Conhecimento é influenciada por fatores de ordens diversas, favoráveis, portanto, à criação, ao uso, bem como ao compartilhamento de informações e conhecimento, o que demanda um alinhamento para que missão, visão e objetivos sejam alcançados (ALVARENGA NETO, 2008).

As questões culturais que permeiam o ambiente organizacional como um todo podem influenciar na implantação da cultura da gestão do conhecimento na organização como um todo. A fim de que essa cultura possa ser colocada em prática de uma forma mais efetiva, as estratégias de comunicação empresarial se tornam relevantes, visto que fazem com que a troca entre experiências, vivências, visões e perspectivas se dê de uma forma constante, significativa e fluida. Portanto, concluise que a comunicação empresarial é a chave para construir bons relacionamentos entre líderes e liderados em uma empresa. Já a falta de uma comunicação interna eficaz atrapalha o fluxo de informações importantes, interfere no clima organizacional e facilita a transmissão de boatos (TAVARES, 2010). Por isso, investir nessa área é fundamental para alimentar o espírito de equipe, manter os funcionários satisfeitos e elevar a produtividade (TIBURCIO; SANTANA, 2014).

RC: 103793

Disponível em:

https://www.nucleodoconhecimento.com.br/comunicacao/conhecimento-nas- 


\section{ABORDAGENS RELACIONADAS À GESTÃO DO CONHECIMENTO}

\subsection{ABORDAGEM SOCIOLÓGICA OU COMPORTAMENTAL}

Batista (2004) entende que esta abordagem não restringe-se apenas à área de sociologia. Embora não seja muito explorada e mesmo que não seja disciplinada, entende-se que qualquer indivíduo é parte de um grupo, que tem suas regras, valores, objetivos, necessidades de comunicação e troca de experiências, sendo fatores importantes a serem levados em consideração no processo de gestão do conhecimento.

\subsection{ABORDAGEM ECONÔMICA}

Diferentemente da abordagem sociológica, a economia foca, preferencialmente, nas competências que existem dentro da organização. Para esta abordagem, uma gestão de conhecimento efetiva deve identificar de forma exaustiva todo o conhecimento existente dentro da organização, portanto, as competências devem ser mantidas e cultivadas de forma contínua, bem como devem estar disponíveis para toda a organização (BATISTA, 2004). Nesta abordagem, as TICs são vistas como ferramentas que armazenam, localizam e dão acesso às competências organizacionais, sobretudo por meio da Internet, suportada por sistemas de informação apoiados pelas TICs, que pode de alguma forma chamar de SAD.

\subsection{ABORDAGEM TECNOLÓGICA}

A terceira grande abordagem a gestão do conhecimento enfatiza a representação do conhecimento como forma de facilitar o seu armazenamento e disponibilização para a organização (CHINEM, 2017). Segundo esta abordagem, todos os indivíduos devem estar motivados a expressar o seu conhecimento para que a sua representação seja a mais legitima possível (MACARENCO; TERCIOTTI, 2017).

RC: 103793

Disponível em:

https://www.nucleodoconhecimento.com.br/comunicacao/conhecimento-nas- 
Assim, a de gestão de conhecimento assenta na identificação de conhecimento relevante, sua representação, armazenamento em bases de conhecimento e disponibilização para todos os que dele dependem para tomarem decisões (TAVARES, 2010).

Segundo Batista (2004), pode-se perceber que a atividade central desta abordagem é o armazenamento e recuperação. Pretende-se, portanto, minimizar o impacto que a saída de especialistas possa causar sore a organização e estimular a aprendizagem de novos indivíduos. As TICs usadas nesta atividade são aquelas que já foram descritas nesta memória, as bases de dados, Dtawarre Houses, OLAP, Data Mining, em suma, sistemas informáticos que ampliam as capacidades de memória e raciocínio dos indivíduos e grupos, inseridos numa organização.

Nesta abordagem, pode-se verificar, facilmente, como é que a estrutura de um sistema de BI se enquadra no processo de gestão de conhecimento. Este sistema sido desenvolvido para apoiar a criação de novos conhecimentos, tendo como objetivo melhorar processos, identificar e interpretar padrões em grandes volumes de informação, assim como foca-se na localização de competências e partilha de experiências (BUENO, 2009).

\section{O CONTRibuto dA Gestão de CONHECIMENTO PARA A EFICIÊNCIA ORGANIZACIONAL}

Como se pode imaginar, medir o grau de eficiência em uma organização é bastante complicado, controverso, já que os pensadores sobre a matéria não são consensuais no que tange aos critérios dessa medição (BATISTA, 2004). As organizações são realidades sociais bastante complexas e em constante mutação, de modo que medir a sua eficiência se torna bastante complexo (TAVARES, 2010). Mas pode ter-se uma noção do grau de eficiência de uma organização relacionando esta a sua capacidade perante os seguintes aspectos (Turban; Aronson, 2001; Gil, 2008):

RC: 103793

Disponível em:

https://www.nucleodoconhecimento.com.br/comunicacao/conhecimento-nas-

organizacoes 
- Capacidade de atingir metas - esta medida recai sobretudo nas vendas, unidades produzidas, lucros gerados e melhorias na qualidade. Em organizações onde haja uma gestão mais efetiva, existem mecanismos específicos para medir e monitorizar o seu desempenho: avaliação de desempenho individual, avaliação periódica por função, seção, departamento e avaliação de processos-chave de negócios;

- Capacidade de resolver problemas - o foco é colocado no processo de tomada de decisões. Os critérios podem ser: versatilidade/flexibilidade dos funcionários, áreas de especialização mesmos, quota de mercado, capacidade de produção e capacidade de resposta;

- Capacidade de satisfazer clientes - este critério prende-se à capacidade de satisfazer entidades externas, cuja relação é essencial para o sucesso da organização. A satisfação dessas entidades que podem ser clientes, fornecedores, instituições governamentais ou reguladoras pode ser medida por meio do grau de correção de encomendas dos clientes, entregas dentro de prazos, repetição de negócio, queixas dos clientes e processos no tribunal.

- Capacidade de melhorar processos internos - neste caso, uma organização é eficiente quando é capaz de reformular os seus processos de forma a assegurar que são executados de maneira contínua e correta. Os critérios para esta medição são: custo e tempo de execução de processos, forma como os processos se interligam, fluidez de matérias e informação e a criação de soluções inovadoras.

- Capacidade de satisfazer vários agentes organizacionais - refere-se à informação qualitativa e à rotatividade dos recursos humanos. Os seus critérios, embora subjetivos, podem ser: participação em equipes de trabalho, satisfação com o trabalho realizado, motivação e compromisso, absentismo, greves e ações disciplinares.

Apesar desses cinco aspectos serem bastante abrangentes, como é que a gestão do conhecimento pode, então, contribuir para a eficiência da organização? Pereira e Fonseca (1997) referem que, no caso da gestão do conhecimento, a performance da RC: 103793 
organização pode ser incrementada de forma genérica com o aumento das capacidades de aprendizagem, escolha de alternativas de ação, planeamento e execução de soluções eficazes para os problemas que se apresentam e criação de novas ideias de negócio passiveis de serem traduzidas em serviços ou produtos que satisfaçam as necessidades das envolventes transacional e contextual.

\section{CONSIDERAÇÕES FINAIS}

Retomando a questão norteadora: Qual a importância da gestão do conhecimento nas organizações? Conclui-se que a sociedade moderna e, consequentemente, o mercado, têm sido marcados por transformações constantes e rápidas, pela abundância de informações, bem como de conhecimentos, e, ainda, pelas evoluções tecnológicas diárias. Saber como colocar em prática o conhecimento e convertê-lo em ações efetivas é o grande desafio das corporações, uma vez que o mundo corporativo é influenciado por questões socioeconômicas, políticas e culturais, o que impõe, às organizações, a necessidade de se adaptarem a esse novo contexto para que consigam garantir a sua sobrevivência. Diante desse cenário, as organizações mais dinâmicas têm redefinido as suas estruturas, processos, técnicas, instrumentos e sistemas com o intuito de fazerem um uso mais apropriado do conhecimento, por este motivo, a gestão do conhecimento é um elemento primordial nas organizações.

Este artigo demonstrou que a importância do campo da Gestão do Conhecimento reside nas ações que fomenta, sendo elas os processos voltados à criação, identificação, atualização, disseminação, transferência e armazenamento do conhecimento considerado como relevante e estratégico para as organizações. A Gestão do Conhecimento, nesse contexto, ressalta a sua relevância ao promover o uso ampliado do conhecimento humano, individual, convertido em conhecimento coletivo, sendo considerado como uma tarefa a ser assumida por todos os colaboradores de uma entidade. Essa participação global dos funcionários é essencial ao bom desempenho das ações, programas e estratégias promovidas por este campo.

RC: 103793

Disponível em:

https://www.nucleodoconhecimento.com.br/comunicacao/conhecimento-nas- 
A pesquisa frisou que o controle da gestão do conhecimento é essencial ao aumento de desempenho de uma empresa, uma vez que ele visa monitorar os processos de decisão, comunicação, colaboração, negociação e recompensa e busca, ainda, assegurar que a ação individual e coletiva seja apoiada nos recursos necessários (TIC) para se tornar eficaz, sem esquecer a valorização da experimentação e partilha de conhecimentos. Pode-se concluir que a Gestão do Conhecimento possa ser colocada em prática de forma efetiva, a organização, em primeiro lugar, deve compreender os sujeitos organizacionais que integram aquele corpo e, a partir disso, deve analisar como esses têm buscado, acessado, apropriado e compartilhado o conhecimento com os demais, uma vez que a troca de experiências e vivências é fundamental à eficiência desse campo no dia a dia organizacional. Com esta conscientização, é papel da organização criar uma cultura organizacional que alicerce os processos de criação e troca do conhecimento. Isto faz com que os colaboradores se sintam motivados e confiem que o seu conhecimento será compartilhado e valorizado.

\section{REFERÊNCIAS}

ALFENAS, R. A. da. S. et al. Gestão do conhecimento nas organizações brasileiras: revisão e bibliometria de obras no período de 2008 a 2017. Revista do Serviço Público (RSP), v. 72, n. 2, p. 452-478, 2021.

ALVARENGA NETO, R. Gestão do conhecimento em organizações: proposta de mapeamento conceitual integrativo. São Paulo: Saraiva, 2008.

BATISTA, E. de. O. Sistema de informação: o uso consciente da tecnologia para o gerenciamento. São Paulo: Saraiva. 2004.

BUENO, W. da. C. As transgressões conceituais em Comunicação Empresarial. Organicom, v. 6, n. 10-11, p. 121-127, 2009.

RC: 103793

Disponível em:

https://www.nucleodoconhecimento.com.br/comunicacao/conhecimento-nasorganizacoes 
CHINEM, R. Introdução à comunicação empresarial. São Paulo: Saraiva Educação SA, 2017.

CHOO, C. W. A organização do conhecimento: como as organizações usam a informação para criar significado, construir conhecimento e tomar decisões. São Paulo: Editora Senac, 2003.

GIL, A. L. Sistema de informação contábil-financeira. $3^{\underline{a}}$ ed. São Paulo: Saraiva, 2008.

GUTIÉRREZ, M. P. M. Gestión del conocimiento en las organizaciones. Gijón: Tréa, 2008.

MACARENCO, I.; TERCIOTTI, S. H. Comunicação empresarial na prática. Saraiva Educação SA, 2017.

MATTERA. T. C. Gestão do conhecimento na prática. In: SOUTO, L. F. (Org.). Gestão da informação e do conhecimento: práticas e reflexões. Rio de Janeiro: Interciência, 2014. p. 199-220.

MENEZES, K. C. de. et al. Gestão do conhecimento nas organizações: uma aprendizagem em rede colaborativa. Perspectivas em Gestão \& Conhecimento, v. 7, p. 145-159, 2017.

MOLINA, L. G. Gestão do conhecimento aplicada aos portais corporativos. In: VALENTIM, M. L. P. (Org.). Ambientes e fluxos de informação. São Paulo: Cultura Acadêmica, 2010. p. 123-156.

NONAKA, I. A empresa criadora de conhecimento. In: TAKEUCHI, H.; NONAKA, I. (Orgs.). Gestão do conhecimento. Porto Alegre: Bookman, 2008. p. 39-53.

PEREIRA, M. J. .L. .B.; FONSECA, J. G. M. Faces da decisão: as mudanças de paradigmas e o poder da decisão. São Paulo: Makron Books, 1997.

RC: 103793

Disponível em:

https://www.nucleodoconhecimento.com.br/comunicacao/conhecimento-nas- 
SANTOS, M. Y.; RAMOS, I. Business intelligence. Tecnologias de informação na gestão de conhecimento. Lisboa: FCA - Editora Informática, 2006.

SANTOS, V. C. B. Competência em informação na construção da inteligência competitiva nas organizações: o caso da empresa Mizumo (Pompéia/SP). 2014. 178f. Dissertação (Mestrado) - Programa de Pós-Graduação em Ciência da Informação, Faculdade de Filosofia e Ciências, Universidade Estadual Paulista (Unesp), Marília, SP, 2014.

SANTOS, V. C. B. dos.; DAMIAN, I. P. M.; VALENTIM, M. L. P. A cultura organizacional como fator crítico de sucesso à implantação da gestão do conhecimento em organizações. Informação \& Sociedade, v. 29, n. 1, p. 51-66, 2019.

STRAUHS, F. do. R. Gestão do conhecimento nas organizações. Curitiba: Aymará, 2012.

TAVARES, M. Comunicação empresarial e planos de comunicação. São Paulo: Atlas, 2010.

TIBURCIO, S. J.; SANTANA, L. C. de. A comunicação interna como estratégia organizacional. Revista de Iniciação Científica Cairu, v. 1, p. 13-26, 2014.

TURBAN, E.; ARSONSOM, J. Decision support systems and Inteligent Systms. Upper Saddle River, NJ : Prentice Hall, 2001.

VALENTIM, M. L. P. Gestão da informação e do conhecimento no âmbito da Ciência da Informação. São Paulo: Polis; Cultura Acadêmica, 2008

Enviado: Outubro, 2021.

Aprovado: Dezembro, 2021.

RC: 103793

Disponível em:

https://www.nucleodoconhecimento.com.br/comunicacao/conhecimento-nas- 